\title{
An Integrated Approach to Teaching Literature in an EFL Classroom
}

\author{
Supaporn Yimwilai ${ }^{1}$ \\ ${ }^{1}$ Department of Western Languages Department, Srinakharinwirot University, Bangkok, Thailand \\ Correspondence: Supaporn Yimwilai, Department of Western Languages Department, Srinakharinwirot \\ University, 114 Sukhumvit 23, Bangkok 10110, Thailand. Tel: 66-87083-6200. E-mail: supapoy2@hotmail.com
}

\author{
Received: October 7, 2014 Accepted: November 17, 2014 Online Published: January 20, 2015 \\ doi:10.5539/elt.v8n2p14 URL: http://dx.doi.org/10.5539/elt.v8n2p14
}

\begin{abstract}
This research studied the effectiveness of the integrated approach in English as a Foreign Language (EFL) classrooms and how it related to students' 1) achievements, 2) critical thinking skills, and 3) attitudes toward reading literature. To ensure that the results were accurate and reliable, the experiment was conducted in two different regions. It was found that the results from both locations were similar. Specifically, the achievement test scores, critical thinking skills improvement, and attitudes toward reading literature of the experiment groups were significantly higher than those of the control groups. This indicated that the integrated approach was effective.
\end{abstract}

Keywords: an integrated approach, critical thinking skills, teaching literature, EFL students

\section{Introduction}

Many scholars have argued the effectiveness of the use of literature in English as a Foreign Language (EFL) classrooms. Those against its use argue that the language used in literature is structurally complex, conceptually difficult to understand, and unique to a particular culture or authentic situation and therefore does not support the goals of teaching grammar or helping students meet their academic and occupational needs (Kay, 1982). However, others counter these reservations with their own arguments. Van (2009), for example, believes studying literature in an EFL classroom is beneficial for many reasons: it provides meaningful context; involves a profound range of vocabulary, dialogue, and prose; appeals to the imagination and enhances creativity; encourages critical thinking; and is in line with Communicative Language Teaching principles.

Literature has been a subject of study in many countries; unfortunately, until recently it has not been given much emphasis in the EFL classroom. Despite this deficiency, there have been a few studies on teaching literature to EFL students. For example, Mujumdar (2010) concludes that when teaching English literature in non-native contexts, both teachers and learners face difficulties due to historical, cultural, racial, and linguistic differences. Marshall (as cited in Bernhardt, 2001, p. 60) notes that there are no systematic studies on how literature teaching to EFL students at the university level proceeds. This reveals the necessity of carrying out further study to shed light on how literature should be dealt with in EFL classrooms.

This study, therefore, demonstrates the value of teaching literature in EFL classrooms if it is taught properly. As Mujumdar suggests, "the answer can be made positive, provided certain precautions are taken and improvements are made in the methods of teaching" (2010, p. 212). For literature teachers, it is important that their methods and approaches aim toward the all-around development and welfare of students. Some scholars suggest that an integrated approach is a good option for effective instruction, especially in language teaching (Adeyemi, 2010, p. 19). Moreover, such an approach is vital in the present era of globalization, as many believe that the world, a culturally and linguistically diverse entity, can be best understood in an integrated way. Therefore, this study investigates the extent of its use in actual instruction practice, studying the effectiveness of the integrated approach to teaching literature upon students' achievement, critical thinking skills, and attitudes toward reading literature.

\section{Literature Review}

\subsection{The Concept of the Integrated Approach}

The integrated approach can also be referred to as the multidisciplinary approach, which denotes the teaching of concepts across more than one subject area or approach. Adeyemi $(2010$, p. 9) explains that in this approach, teachers combine a variety of methods, techniques, and technical devices. Integration, in this sense, means using 
relevant ideas from many disciplines or approaches. Aina (1979) posits that integration can be used within and across disciplines. For example, language can either be taught within itself by focusing on the four skills of listening, speaking, reading, and writing or across disciplines by integrating concepts, themes, and ideas from different subjects.

The integrated approach is beneficial to students. Langa and Yost $(2007$, p. 65) state that this methodology helps students make connections. Lucan (1981, p. 59) further suggests that the integrated approach is student-centered because it empowers students to make connections, generalize, and transfer knowledge to a variety of problem-solving situations in the real world. In addition, Adeyemi (2010, p. 12) writes that the integrated approach provides students with more comprehensive learning that is rich and interesting. As a result, it makes the classroom atmosphere more enjoyable and thought-provoking. Moreover, Knowles and Smith explain that the integrated approach to teaching literature "can facilitate collaborative learning as well as help students become independent problem solvers" (2001, p. 77).

\subsection{Approaches to Teaching Literature}

According to Carter and Long (1991), the three main approaches to teaching literature are the language model, the cultural model, and the personal growth model. These are outlined in the following subsections.

\subsubsection{Language Model}

The most common approach to teaching literature in the EFL classroom is what Carter and Long (1991) refer to as the language-based approach. This model helps EFL students enhance their knowledge of the target language by working on familiar grammar, lexical, and discourse categories, indirectly paving the way for a better understanding of a text and the formulation of meaningful interpretations. These will facilitate a sensible and aesthetic appreciation of a text. Such an approach enables students to access a text in a systematic and methodical way to study examples of specific linguistic features, literal and figurative language, and direct and indirect speech. This approach lends itself to the repertoire of activities used in EFL teaching - such as the cloze procedure, prediction exercises, jumbled sentences, summary writing, creative writing, and role play - that are used by teachers to deconstruct literary texts in order to serve specific linguistic goals.

\subsubsection{Cultural Model}

The cultural model helps EFL students deal with a literary work in relation to the target culture, such as literary history or genre. It requires that students explore and interpret the social, political, literary, and historical context of a specific text. This model provides an opportunity for students to explore cultural background, which leads to a genuine understanding of literary works and encourages students to understand different cultures and ideologies in relation to their own.

\subsubsection{Personal Growth Model}

The personal growth model, or enrichment model, attempts to bridge the language model and the cultural model by focusing on the particular use of language in a text while simultaneously placing it in a specific cultural context. This model involves students' personal, intellectual, and emotional experiences. Students are encouraged to express their feelings and opinions and to make connections between their own personal and cultural experiences and those expressed in the text. Another aspect of this model is that it helps students develop knowledge of ideas and language - content and formal schemata - through different themes and topics. This function relates to the theories of reading expressed by Goodman (1970), which emphasize the interaction of readers with texts. As Cadorath and Harris point out, "text itself has no meaning; it only provides direction for reader to construct meaning from the reader's own experience" (1998, p. 188). Thus, learning is said to take place when readers are able to interpret texts and construct meaning on the basis of their own experience.

From the above discussion, it can be said that these three models of teaching literature differ in terms of their focus on texts. In the language model, texts are used as a focus for grammatical and structural analysis; in the cultural model, texts are used as cultural artifacts, and in the personal growth model, texts are considered a stimulus for personal growth activities. Each approach has different strengths and weaknesses. For example, Savvidou (2004) comments that the cultural model tends to be teacher-centered, and there is little opportunity for extended language work. Therefore, what is needed is an integrated approach model comprising key elements of all three models so that literature becomes accessible to EFL students and most beneficial for their development. 


\section{Method}

\subsection{Participants}

The participants in this study consisted of 78 Thai students majoring in English at two universities in different geographical locations, Bangkok and PathumThani; these locations were selected using purposive sampling, as the selection of participants from different environments and cultures would ensure the reliability and accuracy of the results. The participants at each university were divided into two groups: the experimental group and the control group.

\subsection{Instruments}

A lesson plan was created to teach literature using the integrated approach. The method of teaching was divided into three phases. In the first phase, Language Consideration, students were assigned a literary text that they were to take home and read, along with a vocabulary list and vocabulary items (containing cultural meanings). In the second phase, Cultural Consideration, the instructor provided necessary background and cultural information to the class in a pre-reading stage. In the third phase, Enrichment Consideration, the class held a discussion with the help of the instructor. Then, students were asked to do post-reading activities such as writing and language activities.

An achievement test was developed to compare the literature knowledge of students in the experimental group to that of the control group after the experiment. A set of critical thinking skills test was also developed to measure five levels of critical thinking skills: 1) understanding or comprehension; 2) analyzing arguments, claims, or evidence; 3) making inferences using inductive or deductive reasoning; 4) judging or evaluating; and 5) making decisions or solving problems.

Finally, a set of questionnaires to study students' attitudes toward reading literature was prepared for students in the experimental group and in the control group. It included 15 items and was divided into three parts: opinions, feelings, and inclination to action.

The researcher asked specialists to review the instruments in order to determine their validity. Each specialist determined whether each instrument was valid and also commented on the language use. The reliability and item facility were determined in the pilot phase study. The Cronbach's Alpha coefficient for the reliability of the achievement test, critical thinking skills test, and questionnaires to study students' attitudes toward reading literature was $0.769,0.86$, and 0.832 respectively.

\subsection{Data Collection Procedures}

The study was divided into two phases. The first phase was conducted at a university in Bangkok (UB) and the second at a university in PathumThani (UP). Each phase was executed as follows.

In the first week, the students in the experimental group and in the control group were asked to complete a pretest about critical thinking skills. Soon after the pretest, the experiment and control groups were taught, using a different method for each, for a period of eight weeks. Each teaching session lasted two and a half hours. Students in the experimental group were taught using lesson plans based on the integrated approach. Students in the control group were taught using the conventional method, which refers to an instructor-led approach that consists of the one-sided discourse of the instructor and the passive response of the students; also, the instructor focuses only on the elements of literature rather than the literature itself. After teaching eight sessions, the students in both groups were asked to complete the achievement test, the critical thinking skills test, and the questionnaires to study their attitudes toward reading literature.

\subsection{Data Analysis}

The data from the achievement test and the critical thinking skills test were scored. The answer of essay questions were scored by two raters using a scoring rubric adapted from Peter Facione and Noreen Facione's Holistic Critical Thinking Scoring Rubric. When the two raters' scores differed by more than one point, a third reader scored the essay. Then the scores of each student from all raters were combined and changed to a mean score. The mean scores of all students were analyzed using mean scores, standard deviations, a two-way analysis of variance, and a three-way analysis of variance with one repeated measure. The data obtained from the questionnaires were analyzed using mean scores, standard deviation, and a t-test analysis.

\section{Results}

\subsection{Achievement}

The mean scores of the achievement tests from both universities are presented in Table 1 . 
Table1. Descriptive statistics of achievement

\begin{tabular}{lllll}
\hline \multirow{2}{*}{ School } & \multicolumn{3}{l}{ Group } & \multicolumn{3}{l}{ Experiment } \\
\cline { 2 - 5 } & Control & SD & $\mathrm{M}$ & $\mathrm{SD}$ \\
\cline { 2 - 5 } & $\mathrm{M}$ & 9.50 & 40.74 & 5.09 \\
UP & 35.42 & 4.79 & 43.50 & 6.66 \\
UB & 36.74 & 7.48 & 42.12 & 6.03 \\
Total & 36.08 & & & \\
\hline
\end{tabular}

As shown in Table 1, at UP, the mean score of the control group was 35.42 and the mean score of the experimental group was 40.74. At UB, the mean score of the control group was 36.74 and the mean score of the experimental group was 43.50. To compare the achievement score after instruction of the experimental group to that of the control group, a two-way analysis of variance was used. The results of this analysis are presented in Table 2.

Table 2. Comparison of achievement among university groups

\begin{tabular}{lllllll}
\hline Source of Variance & df & SS & MS & F & Sig. & $\eta^{2}$ \\
\hline School (UP-UB) & 1 & 104.04 & 104.04 & 2.27 & .135 & .023 \\
Group (Control-Experiment) & 1 & 912.04 & 912.04 & 19.87 & .000 & .172 \\
School * Group & 1 & 12.96 & 12.96 & .28 & .596 & .003 \\
Error & 96 & 4405.96 & 45.90 & & & \\
Total & 100 & 158316.00 & & & & \\
\hline
\end{tabular}

Table 2 reveals the effectiveness of the integrated approach. At both universities, the results were $\operatorname{similar}(\mathrm{F}=.28$, $\mathrm{p}=.596)$; that is the achievement scores of the students in the experimental groups were significantly higher than those of the control groups, at the level $.05(\mathrm{~F}=19.87 \mathrm{p}<.001)$. The effect size was .172 .

\subsection{Critical Thinking Skills}

The mean pretest and posttest scores of groups at both universities are presented in Table 3.

Table 3. Descriptive statistics of critical thinking skills

\begin{tabular}{lllllll}
\hline \multirow{2}{*}{ University } & Group & $\mathrm{N}$ & Pretest & \multicolumn{3}{c}{ Posttest } \\
\cline { 5 - 7 } & & Mean & SD & Mean & SD \\
\hline \multirow{2}{*}{ UP } & Experimental & 24 & 12.08 & 3.16 & 20.00 & 2.00 \\
& Control & 24 & 16.25 & 2.97 & 17.54 & 2.48 \\
\multirow{2}{*}{ UB } & Experimental & 15 & 22.67 & 2.35 & 27.73 & 2.08 \\
& Control & 15 & 23.71 & 3.65 & 24.29 & 3.17 \\
\hline
\end{tabular}

To compare the effectiveness of the integrated approach in fostering critical thinking skills at both universities, a three-ways analysis of variance was used to analyze data, and results are shown in Table 4. 
Table 4. Comparison of critical thinking skill improvement among university groups

\begin{tabular}{lllllll}
\hline Source of Variance & $\mathrm{df}$ & $\mathrm{SS}$ & $\mathrm{MS}$ & $\mathrm{F}$ & $\mathrm{p}$ & $\eta^{2}$ \\
\hline Within Subject & & & & & & \\
\hline Pre-Post & 1 & 497.71 & 497.71 & 331.58 & .000 & .820 \\
Pre-Post * School & 1 & 28.78 & 28.78 & 19.17 & .000 & .208 \\
Pre-Post * Group & 1 & 279.23 & 279.23 & 186.02 & .000 & .718 \\
Pre-Post * School * Group & 1 & 10.24 & 10.24 & 6.82 & .011 & .085 \\
Error(Pre-Post) & 73 & 109.58 & 1.50 & & & \\
\hline Between Subjects & & & & & & \\
\hline School & 1 & 2388.75 & 2388.75 & 174.61 & .000 & .705 \\
Group & 1 & 1.08 & 1.08 & .08 & .780 & .001 \\
School * Group & 1 & 38.11 & 38.11 & 2.79 & .099 & .037 \\
Error & 73 & 998.70 & 13.68 & & & \\
\hline & & & & & &
\end{tabular}

The information in Table 4 indicates that when compared to the results of the conventional method, the effect of integrated approach on critical thinking skills of students at UP significantly differed from that of students at UB, at the level of $.05(\mathrm{~F}=6.82 \mathrm{p}<.011)$. The effect size was .085 .

Because the results of the two universities were different, the researcher investigated the effectiveness of the teaching methods in each university individually, as shown in Tables 5.

Table 5. Comparisons between pretest and posttest (pre - post)

\begin{tabular}{llllll}
\hline Group & Group & Mean Difference & SD & $\mathrm{p}$ & $\eta^{2}$ \\
\hline \multirow{2}{*}{ UP } & Control & -1.29 & .35 & .000 & .154 \\
& Experiment & -7.92 & .35 & .000 & .873 \\
\multirow{2}{*}{ UB } & Control & -.57 & .46 & .221 & .020 \\
& Experiment & -5.07 & .45 & .000 & .637 \\
\hline
\end{tabular}

Table 5 shows that at UP, the mean posttest scores of both groups were significantly higher than the mean pretest scores. The critical thinking skill improvement of the control group was 1.29. For the experimental group, the improvement in critical thinking skills was 7.92. The results also revealed that the improvement of the experimental group was significantly higher than that of the control group. At UB, the mean score of the posttest for the control group was not significantly different from those of the pretest, while the mean score of the posttest of the experimental group was significantly higher than those of the pretest. The critical thinking skill improvement of the control group was .57, while that of the experimental group was 5.07. The improvement of the experimental group was significantly higher than that of the control group. The improvements of each group are also shown in Figure 1. 


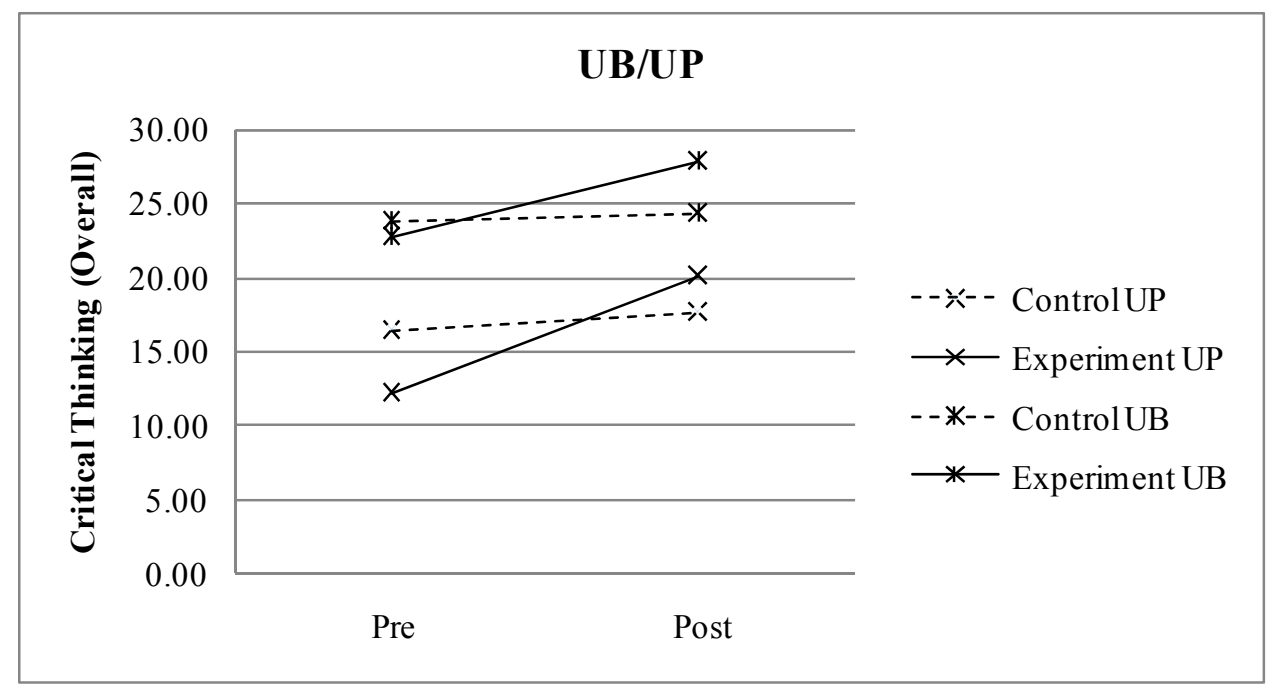

Figure 1. Comparison between pretest and posttest (pre - post)

\subsection{Attitudes toward Reading Literature}

To determine whether the attitudes of students toward reading literature in the experimental group were different from those of the control group, an independent t-test analysis was applied. The results are displayed in Table 6.

Table 6. Comparison of attitudes between experimental and control groups

\begin{tabular}{lllllllll}
\hline University & Group & $\mathrm{N}$ & Mean & $\mathrm{SD}$ & Mean Difference & $\mathrm{df}$ & $\mathrm{t}$ & $\mathrm{Sig}$ \\
\hline \multirow{2}{*}{ UP } & Experimental & 24 & 3.60 & .60 & .51 & 28 & 3.08 & $.005^{* *}$ \\
& Control & 24 & 3.09 & .22 & & & & \\
\multirow{2}{*}{ UB } & Experimental & 15 & 3.79 & .41 & .66 & 28 & 6.00 & $.000^{* * *}$ \\
& Control & 15 & 3.13 & .12 & & & & \\
\hline$* *<.01, * * *<.001$ & & & & & & &
\end{tabular}

Table 6 demonstrates that the attitudes toward reading literature of the students in the experimental groups at both universities were significantly higher than those of the control groups, at the levels of 0.01 and 0.001 , respectively. At UP, the mean score of the experimental group was 3.60 and the mean score of the control group was 3.09. At UB, the mean score of the experimental group was 3.79 and the mean score of the control group was 3.13.

\section{Discussion}

In accordance with many studies, the results of this study clearly prove that the integrated approach is effective. For example, Adeyemi (2010) found that social studies teachers who used the integrated approach performed better than other social studies teachers. The results of the present study also indicate that the integrated approach is more effective than the conventional method. While the findings from both universities were consistent, the results at UP were surprising in that, before the experiment, the critical thinking skills of the students in the experimental group were significantly lower than those of the control group; however, after the experiment, their critical thinking skills became significantly higher. This proves that the integrated approach can be applied to students who have different levels of English proficiency, environments, and cultures.

The suggested approach can inculcate positive attitudes and enhance students' academic achievement and critical thinking skills. As discussed above, the three models for teaching literature- the language model, the cultural model, and the personal growth model - differ in terms of their focus on texts. In the language model, texts are used as a focus for grammatical and structural analysis, in the cultural model, texts are viewed as cultural artifacts, and in the personal growth model, texts are considered a stimulus for personal growth activities. Each approach has different strengths and weaknesses, but the integrated approach used in this study combined the strong points of 
each model. The three stages, Language Consideration, Cultural Consideration, and Enrichment Consideration, assisted students in acquiring language knowledge effectively and facilitated their cultural competence and interpretative abilities. Similar to Adeyemi's idea (2010), this approach empowered students to see connections, generalize, and transfer knowledge to a variety of problem-solving situations in the real world. It also enabled students to gain and apply knowledge to a variety of situations. Therefore, the achievement mean scores and the improvement of critical thinking skills of the experimental groups were higher than those of the control groups.

More importantly, this study points out that the teaching method has a positive impact on students' attitudes toward literature. The findings of this study are not similar to many studies. For example, Bunsom, Singhasiri, and Vungthong (2011, p. 237) write that teachers of literature in Thailand have a hard time pushing their students to read and appreciate literary texts; on the other hand, students believe that literature belongs to inferior students who are not able to do Mathematics or Physics, the subjects which are perceived to be more difficult and therefore more worthy of their trouble. This study proves that teaching methods play a significant role. In the Language Consideration and Cultural Consideration stages, the instructor helped students relate background information to reading, build needed language and background knowledge, and direct students to aspects of the materials that they might enjoy or learn from. Therefore, students did not feel bored or discouraged with the class. In the Enrichment Consideration stage, the instructor planned and facilitated the class while students had the chance to respond to texts and express their ideas. All the prepared activities, similar to Serafini's idea (2001), supported students in their development as independent, lifelong readers. Moreover, the reading was related to other skills such as writing and speaking. Students had the chance to practice using English. Therefore, they felt that this class helped to improve their English and was therefore productive. As a result, like Adeyemi's idea (2001) students enjoyed the activities in class, did not feel bored, and saw the value in studying literature.

The results of this study suggest that teaching literature in EFL classrooms can be useful to students if it is taught properly. More research is needed to support this claim, but based on this study, literature instructors and educators should consider the benefits of the integrated approach.

\section{Acknowledgements}

This research was supported by a grant from Faculty of Humanities, Srinakharinwirot University.

\section{References}

Adeyami, M. B. (2010). A Study of secondary school teachers' view on the teaching of integratedsocial studies in Oyo State of Nigeria (Unpublished doctoral dissertation). ObafemiAwolowo University, Ile-Ife, Nigeria.

Aina, N. F. (1979). Social students for primary school teachers. Ibadan, Nigeria: OxfordUniversity Press.

Bernhardt, E. (2001). Research into the teaching of literature in a second language: What it says and how tocommunicate it to graduate students. SLA and the literature classroom: Fostering dialogues (pp. 195-214). Boston, MA: Heinle \& Heinle.

Bunsom, T., Singhasiri, W., \& Vungthong, S. (2011). Teaching English literature in Thaiuniversities: A case study at King Mongkut's University of Technology Thonburi (pp. 237-252). Paper presented at the 16th English in South-East Asia Conference: English for People Empowerment. Yogjakarta, Indonesia: Sanata Dharma University.

Cadorath, J., \& Harris, S. (1998). Unplanned classroom language and teacher training. ELT Journal, 52(3), 188-196. http://dx.doi.org/10.1093/elt/52.3.188

Carter, R., \& Long, M. (1991). Teaching literature. UK: Longman Group.

Goodman, K. (1970). Reading as a psycholinguistic guessing game. In H. Singer, \& R. Ruddell (Eds.), Theoretical model and processes of reading (pp. 259-272). Newark, NJ: International Reading Association.

Kay, S. (1982). Literature in the ESL classroom. TESOL Quarterly, 16(4), 529-536. http://dx.doi.org/10.2307/ 3586470

Knowles, E., \& Smith, M. (2001). Reading rules! Motivating teens to read. Westport, CT: Libraries Unlimited.

Langa, M. A., \& Yost, J. L. (2007). Curriculum mapping for differentiated instruction. New York, NY: The Dryden Press.

Lucan, T. A. (1981). Social studies as an integrated subject. In H. D. Mehlinger (Ed.), UNESCO handbook for theteaching of social studies. Paris, France: UNESCO.

Mujumdar, S. (2010). Teaching English language and literature in non-native context. Language in India, 10, 210-216. Retrieved from http://www.languageinindia.com/june2010/mujumdarteachingenglish.pdf 
Savvidou, C. (2004). An integrated approach to the teaching of literature in the EFL classroom. The Internet TESL Journal, 12. Retrieved from http://iteslj.org/

Serafini, F. (2001). The reading workshop: Creating space for readers. Portsmouth, NH: Heinemann.

Van, T. T. M. (2009). The relevance of literary analysis to teaching literature in the EFL classroom. English Teaching Forum, 47(3), 2-9. Retrieved from http://eric.ed.gov/?id=EJ923454

\section{Copyrights}

Copyright for this article is retained by the author(s), with first publication rights granted to the journal.

This is an open-access article distributed under the terms and conditions of the Creative Commons Attribution license (http://creativecommons.org/licenses/by/3.0/). 